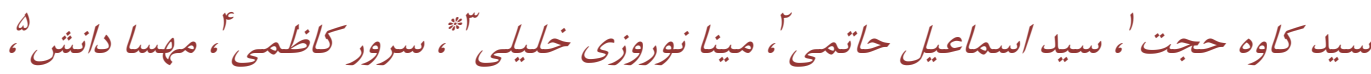

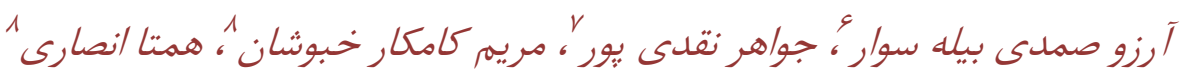

'استاديار روانيزشكى، مركز تحقيقات اعتياد و علوم رفتارى، دانشكاه علوم يزشكى خراسان شمالى، بجنورد، ايران.

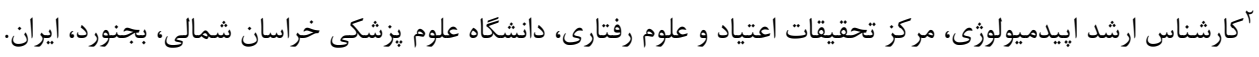

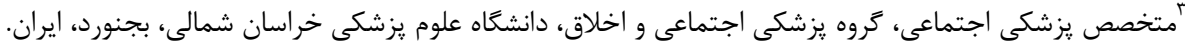

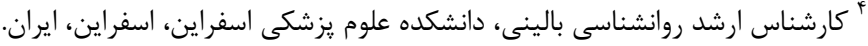

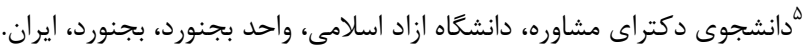

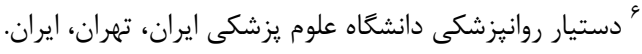

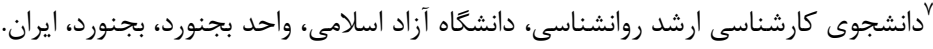

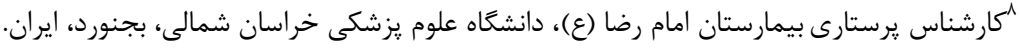

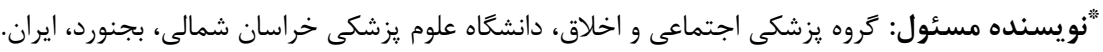
mina.norozi@yahoo.com يست الكترونيك

جكيده

زمينه و هدف: خودكشى يكى /ز عوامل مهم مركى و مير در جهان است و به عنوان يك مشكل بزرك

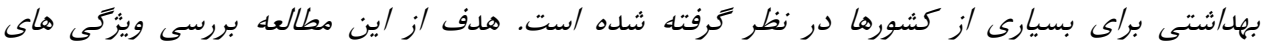

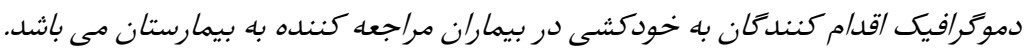

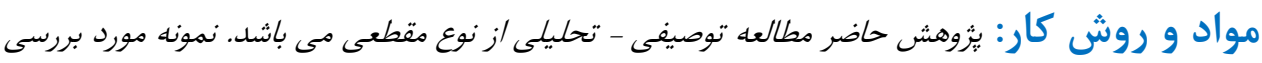

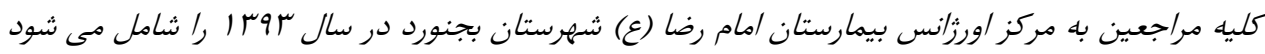

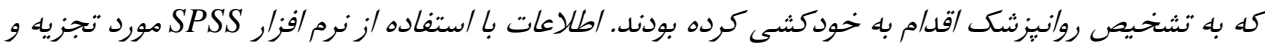

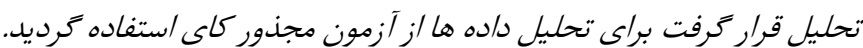

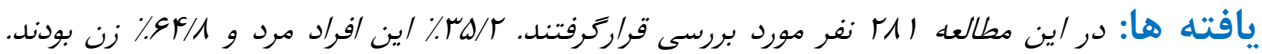

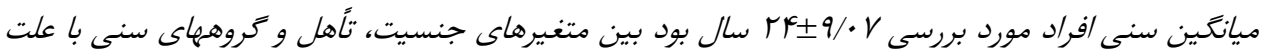

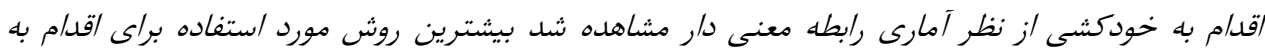

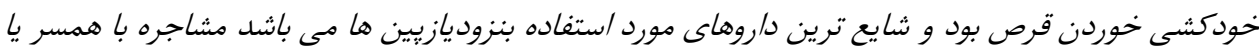

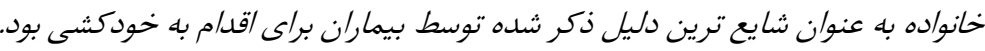

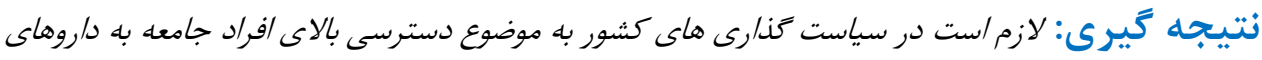

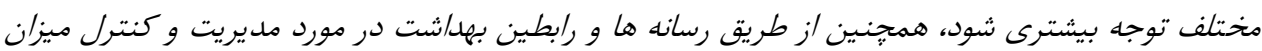

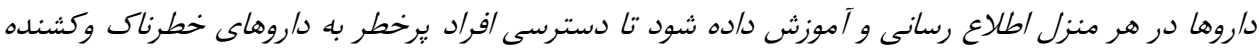
كمتر /تفاق بيافتد. اصلاح: وصول: 
خودكشى در كشورهايى نظير اسكانديناوى، سوئيس،

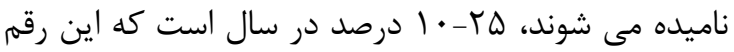

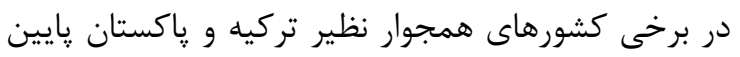
مى باشد. خودكشى در ايران از بيشتر كشورهاى دنيا به نايه ويزه جوامع غربى קايين تر ولى بالاتر از ساير كشورهاى

منطقه خاورميانه است [N، [ب]. بيشتر افرادى كه خودكشى مى كنى كنند، سابقه اقدام به خودكشى دارند و كسانى كه اقدام به خودكشى مى كنيند،

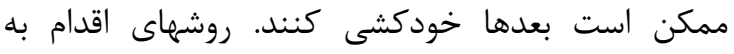
خودكشى نيز در همه جا يكسان نيست و افراد در كشورها، شهرها و مناطق مختلف روشهاى متفاوتى را براى دئ دئ

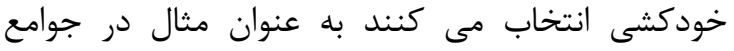

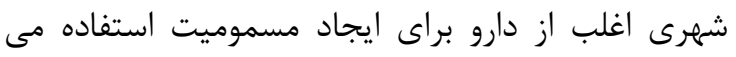
شود و در جوامع روستايى استفاده از سموم و آفت كش ها إنا بسيار متداول تر است. مطالعات انجام شده در سريلانكا يا اطلاعات يزشكى قانونى در هندوستان نشان مى دهد كه

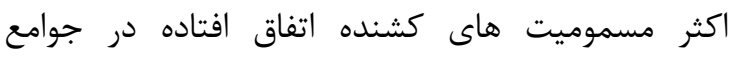
روستايى عمدى بوده و اغلب با استفاده از آفت كش هاى

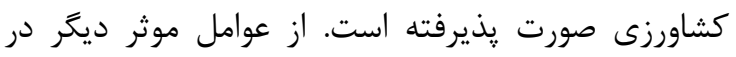
انتخاب روش مسموميت عمدى، رواج و ميزان دسترسى إنى افراد به روان كردان است. نتايج يك بررسى در دريت استراليا

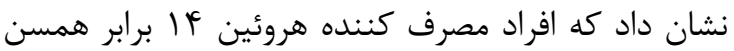

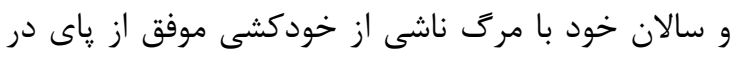
مى آيند. در مطالعه انجام شده در استان كرمان نيز درصد از كل مسموميت هاى مرتبط با خودكشى ناشى از ترياك بوده است، در حالى كه اين ميزان در تهران و داند

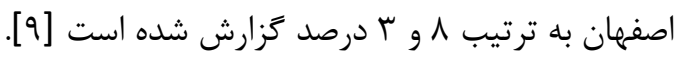
مردان و زنان نيز در به كار بردن شيوه هاى خودكشى با

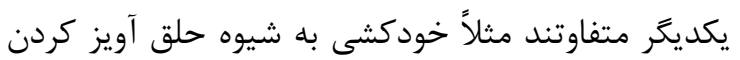

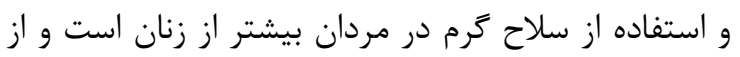

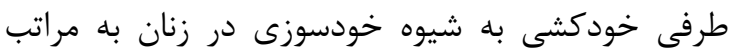
بيشتر از مردان است ولى در خودكشى به شيوه مسموميت درديت

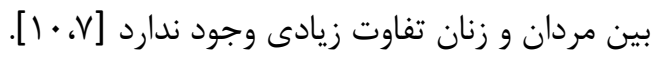

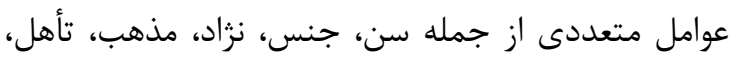

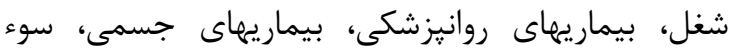

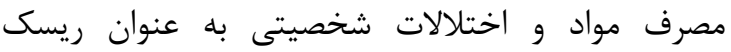

خودكشى يكى از عوامل مهرم مرك و مير در جهان است

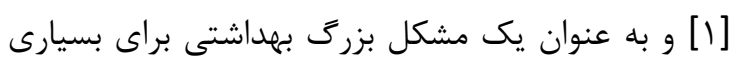

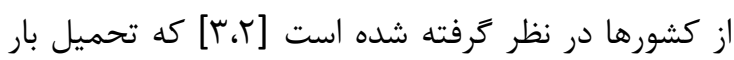

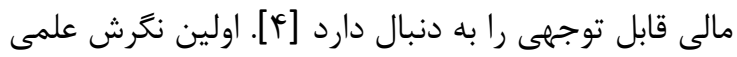

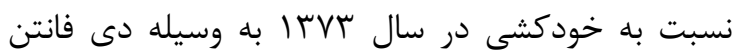

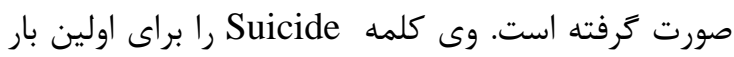

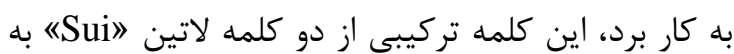

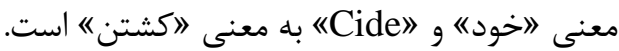

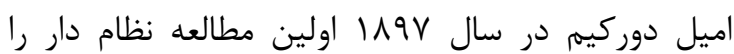

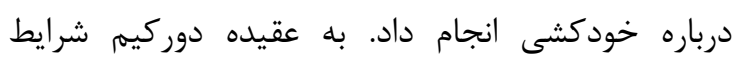
اجتماعى در عصر جوامع صنعتى تا حدود زيادى منشاء داء داء داء ناهنجارى هاى اقتصادى است كه عامل اساسى و مهمى در إدى بروز خودكشى است. اصطلاحاتى كه در مبحث خودكشى رايج ميى باشد عبارتند از: الف) اقدام به خودكشى ( Suicide Attempt Or Act

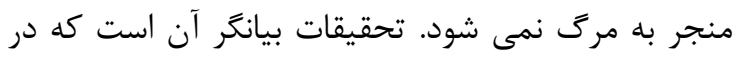

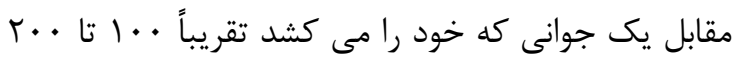
جوان اقدام به خودكشى مى كنند. ب) خودكشى كامل يا

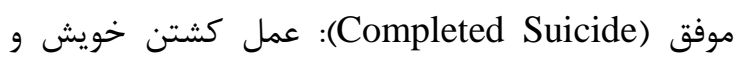
يايان دادن به زندكَى خود به شكل موفق از اصطلاحات

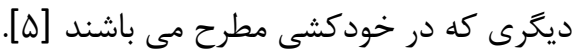

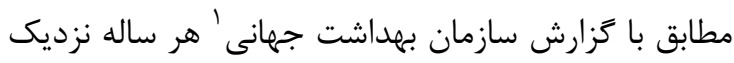

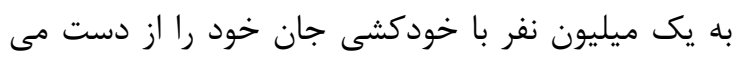
دهند و بيست ميليون نفر اقدام به خودكشى مى كنيند

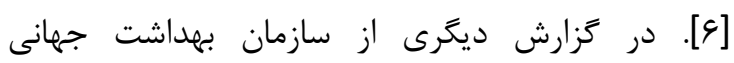

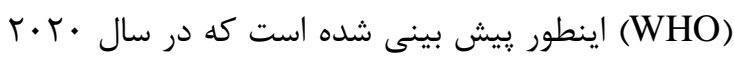

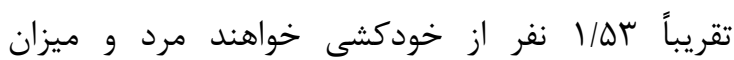

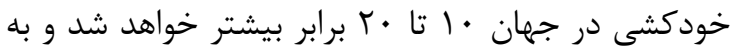

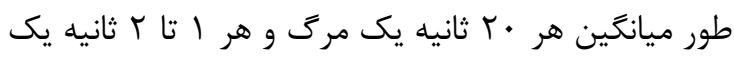

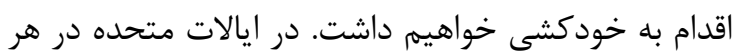

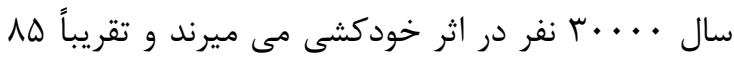

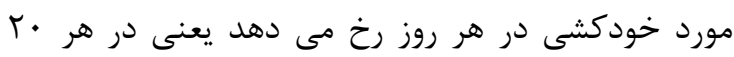

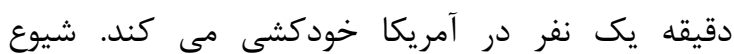

1-World Health Organization 
اضطراب آور زندكى، اختلال خانوادگى، سابقه اقدام به

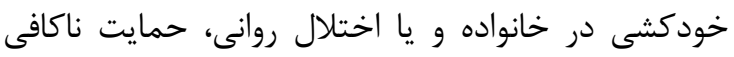
اجتماعى، آسيب هاى اجتماعى و اقتصادى، مشكلات

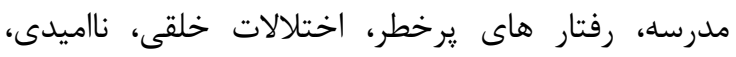
بدبينى و كاهش عزت نفس از عواملى هستند كه خطر

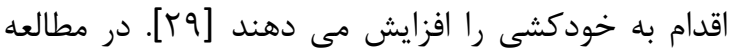
كلوس و همكاران در سال • • · د ديده شد افراد با حمايت اجتماعى پايين، (مخصوصا در ارتباط با همسر) سلامت دان

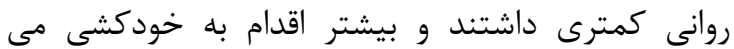

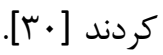

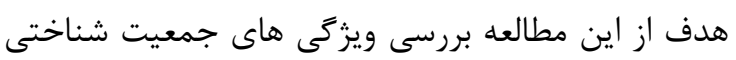

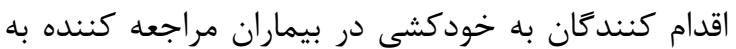

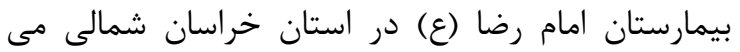

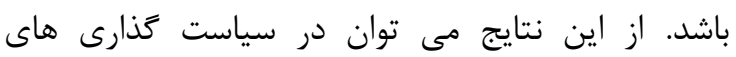
بهداشتى و درمانى اين استان براى ييشخيرى از خودكشى نانى

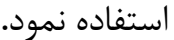

\section{روش كار}

يزوهش حاضر مطالعه توصيفى - تحليلى از نوع مقطعى بوده و نمونه مورد بررسى شامل كليه مراجعينى است كه

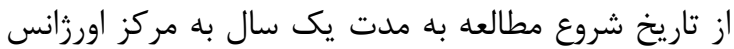

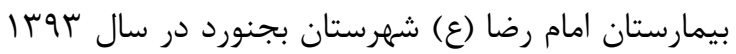

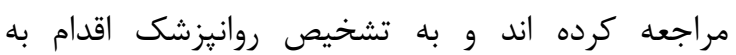
خودكشى كرده بودند مى باشد. اطلاعات مورد نياز به وسيله جك ليست خود ساخته كه شامل اطلاعات دموكرافيك بيماران نظير سن، جنس، تحصيلات، شغل،

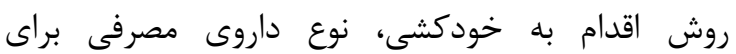
خودكشى، زمان اقدام، وجود يا عدم وجود تصميم قبلى نقي

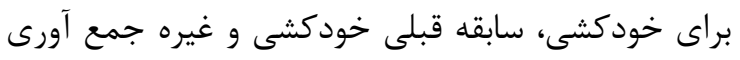
كرديد. همجنين كليه بيماران تحت مصاحبه روانيزشكى قرار كرفته و تشخيص روانيزشكى آنها توسط روانيزشك در

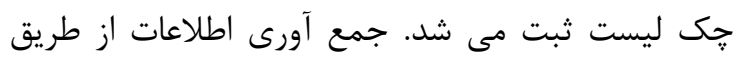

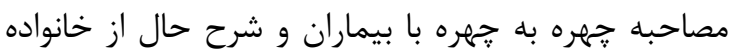
بيماران و توسط سه نفر روانشناس بالينى صورت ترفت. اطلاعات جمع آورى شده با استفاده از نرم افزار آمارى ندان SPSS

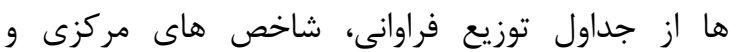
يراكندگى استفاده شد و براى تحليل داده هاى كيفى از
فاكتورهاى اقدام به خودكشى مورد توجه قرار گرفته اند [11]. محيط خانواده مختل كه با شاخصمايى مانند جدايى، طلاق، بيوه گی، دركيرى هاى خانوادگى، استرس

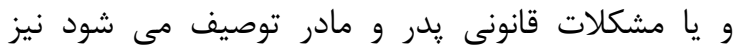

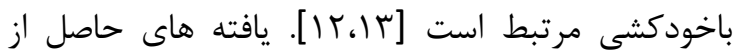
مطالعات كالبد شكافى روحى و روانى از ايالات متحده و

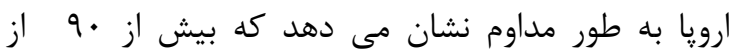
خودكشى هاى كامل در ميان بزركسالان با اختلالات

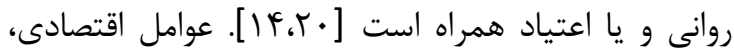
بيكارى، درآمد بايين، وضعيت زناشويى و وجود تاريخجه إنها

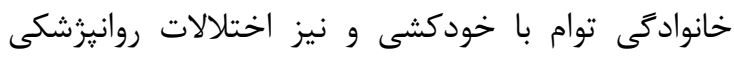
مختلف همجيون افسردگى، اختلالات سلوك، سوءمصرف مواد، اختلالات خوردن، اختلال شخصيت مرزى و اسكيزو

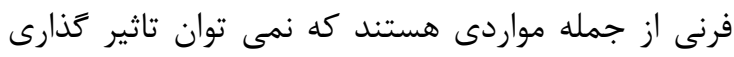

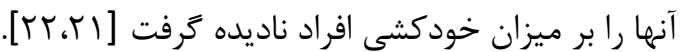
خودكشى دومين علت مرى در بين جوانان است [rآ].

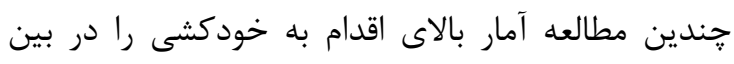

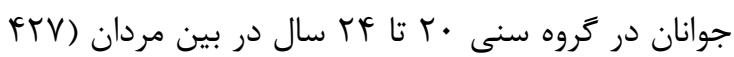

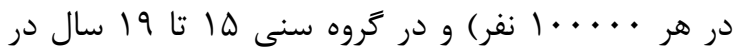

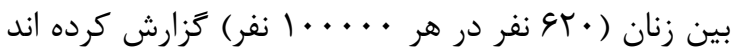

[TY.TY]

تحقيقات نشان مى دهد افرادى كه دست به خودكشى مى زنند داراى مشكلات عمده با همسر، وجود يك فرد جديد در زندَى (همسر دوم)، وجود بيمارى در يكى از اعضاى

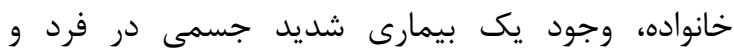
شكست عاطفى مى باشند. دو سوم از افراد متاهل داراى

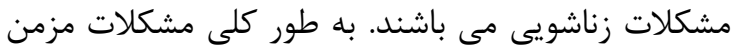

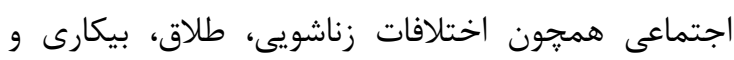

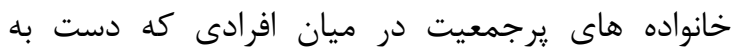

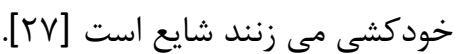

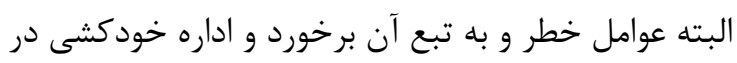
نقاط مختلف متفاوت است، جرا كه بديده باز تاب تراب تاريخجه روانى-فرهنگى جامعه اى است كه در آن رخ مى دهد دهد و

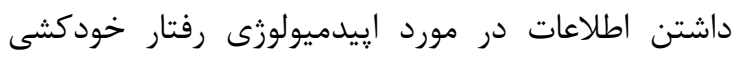

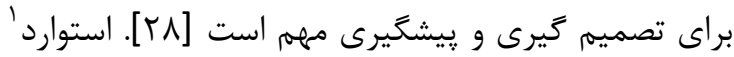

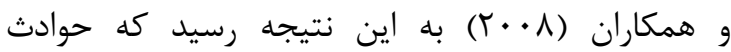

\section{1 -Stewart}


علت اقدام به خودكشى ارتباط معنى دارى با وضعيت

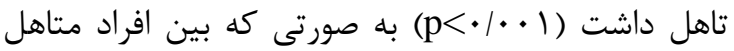

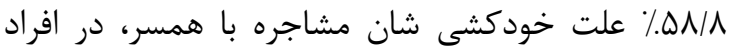

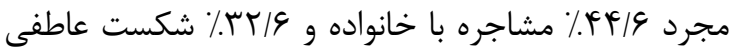

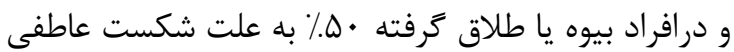
و 1 1 \% مشاجره با خانواده از علل اقدام به خودكشى شان

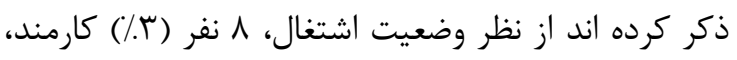

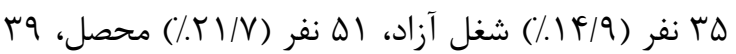

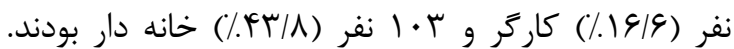
بين وضعيت اشتغال و علت اقدام به خودكشى از نظر

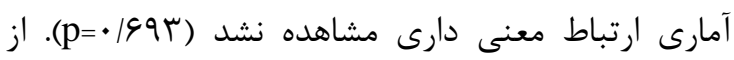
افراد مورد بررسى فقط سب نفر (19/4.) تحصيلات

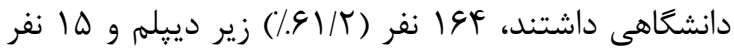
(\$/ه//) بيسواد بودند. بين سطوح تحصيلى و علت اقدام به

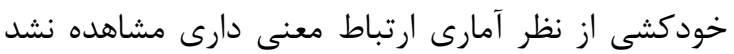

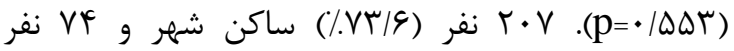

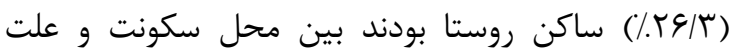
اقدام به خودكشى از نظر آمارى ارتباط معنى دارى

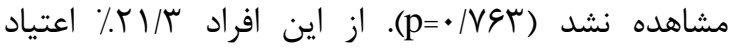

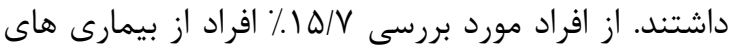

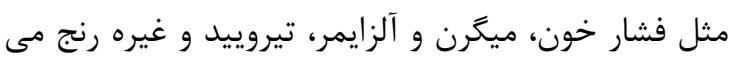

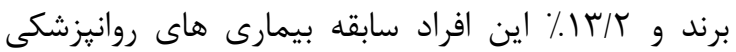
(افسردگى، اختلال شخصيت، دوقطبى، اسكيزوفرنى،

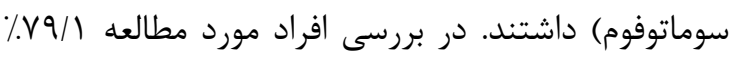

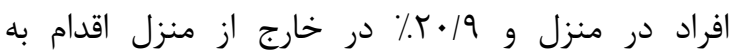
خودكشى نموده بودند.

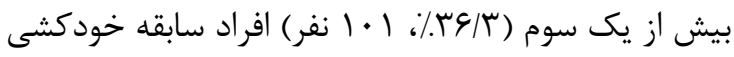

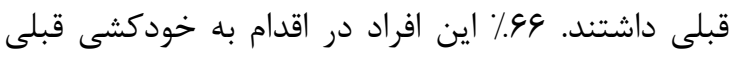
خود از طريق مصرف قرص اقدام كرده بودند و • r/ آنها از طريق حداقل دو روش اقدام به خودكشى كرده بودند. در بررسى روش خودكشى فعلى اين افرد بيشترين روش

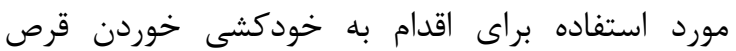

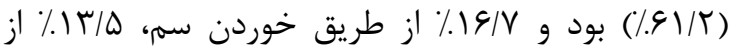
طريق خوردن مواد مخدر و ه/N/ از طريق تركيب خوردن قرص و يك روش ديخر اقدام به خودكشى كرده بودند روش اقدام به خودكشى به تفكيك جنسيت و محل سكونت در جدول ا آورده شده است.
آزمون مجذور كاى استفاده گرديد. سطح معنى دارى در اين مطالعه ه • • • در نظر گرفته شد كليه شركت كنند و بستخان درجه اول (همراه بيمار در بيمارستان) فرم رضايت شركت در تحقيق را تكميل نمودند و به به آنها توضيح داده شد كه اطلاعات بدون ذكر نام بيمار و صرفاً جهت ارزيابى كليه بيماران مراجعه كننده مى باشد و محرمانه بودن اطلاعات شخصى و هويتى بيماران و خانواده آنها توسط روانشناسان و روانيزشك تيم يزوهش اطن حفظ خواهد شد.

1. 1. 1. دراين مطالعه INY نفركه اقدام به خودكشى نموده بودند

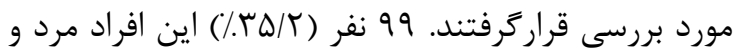

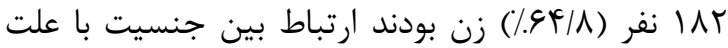
اقدام به خودكشى (بر اساس آنجه خود بيمار به عنوان

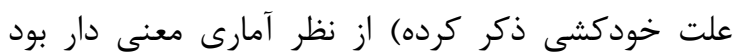

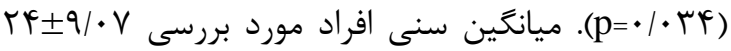

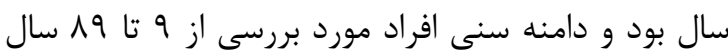

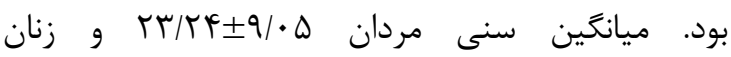
TH/FIN/99

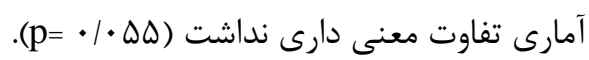
بيشتر افرادى كه به خودكشى اقدام نموده بودند در رده

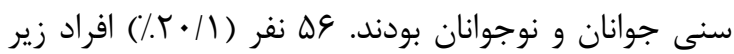

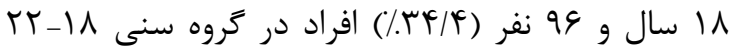

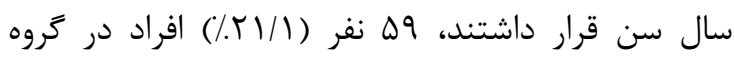

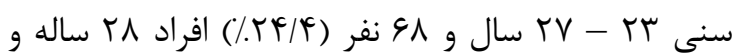
بالاتر بودند ارتباط بين رده هاى سنى با علت اقدام به خودكشى (بر اساس آنجه خود بيمار به عنوان علت

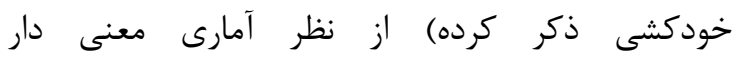
بود(1 • • • p=). مقايسه جنسيتى رده هاى سنى در افراد

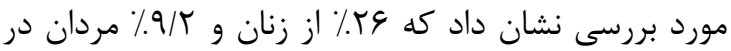
رده سنى زير 11 ال سال بودند و همينطور در رده سنى

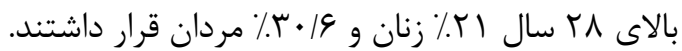

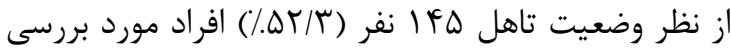

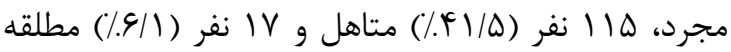
يا بيوه بودند. به طورى كه در مردان اله نفر مجرد،

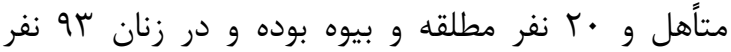
مجرد و • Vفر متأهل و 19 نفر مطلقه و بيوه بوده است. 
جدول ا: مقايسه روش هاى اقدام به خودكشى در بيماران تحت مطالعه

\begin{tabular}{|c|c|c|c|c|c|}
\hline \multirow[t]{2}{*}{ 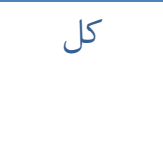 } & \multicolumn{2}{|c|}{ محل سكونت } & \multicolumn{2}{|c|}{ جنسيت } & \multirow{2}{*}{ روش اقدام به خودكشى } \\
\hline & 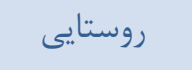 & شهرى & 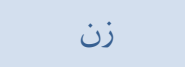 & 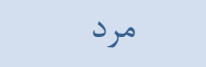 & \\
\hline $\begin{array}{l}\text { IVT } \\
(1 \cdots)\end{array}$ & $r(\% / N / 1)$ & $|f|(\% / A \mid / q)$ & $\begin{array}{c}1 \% \cdot \\
(\% .99 / 1)\end{array}$ & $\operatorname{\Delta r}(\% / \Gamma \cdot T)$ & قرص(شامل ترامادول و غيره ) \\
\hline ev $(1 \cdots)$ & If(\%/rq/V) & $\mu r(\% V T / T)$ & $\mu_{1}(\% .9 \Delta / 9)$ & $19(\% / r)$ & 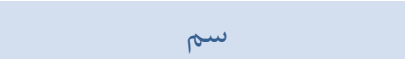 \\
\hline ऍ $(1 \cdots)$ & $9(\% / T r / \varphi)$ & rq(\%Vя/r) & $r \cdot(\% / \Delta r / \varphi)$ & $\backslash \wedge(\% \Psi \vee / \Psi)$ & مواد مخدر (بجز ترامادول) \\
\hline $\operatorname{rF}(1 \cdots)$ & $r \cdot(\% / \Lambda r / r)$ & $f(\%|9| 9)$ & $10(\% / .9 T / \Delta)$ & $q(\%$ IV/D) & تركيب حداقل دو روش \\
\hline$\wedge(1 \cdots)$ & $q(\% \vee \Delta)$ & $r(\% / r \Delta)$ & $r(\% / r / \Delta)$ & $\Delta(\% .9 r / \Delta)$ & مصرف قرص وزدن رگى \\
\hline$\Delta(1 \cdots)$ & $f(\% \cdot \wedge \cdot)$ & $1(\% \cdot r \cdot)$ & $1(\% / \cdot)$ & $f(\% / \wedge \cdot)$ & مصرف قرص وحلق آويز نمودن \\
\hline$r(1 \cdot \cdot)$ & $1(\% \cdot \Delta \cdot)$ & $1(\% \Delta \cdot)$ & $1(\% \Delta \cdot)$ & $1(\% / \Delta \cdot)$ & مصرف قرص وخودسوزى \\
\hline $9(1 \cdots)$ & $9(1 \cdots)$ & - & $r(\% r r / r)$ & $9(\% .9919)$ & ساير روش ها \\
\hline
\end{tabular}

جدول r: انواع داروهاى مورد استفاده براى خودكشى (IT ا بيمار از IVT نفر مصرف بيشتر از يك دسته دارويى داشتند)

\begin{tabular}{|c|c|c|c|}
\hline كل & 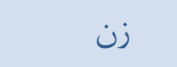 & مرد & دسته داروها \\
\hline $\operatorname{lqr}(r \cdot \mid \Delta)$ & $1 \cdot V(r G / 4)$ & $r q(r \cdot / V)$ & بنزوديازيين ها \\
\hline $94(r \cdot / 1)$ & $\Delta T(1 \Lambda)$ & FI $(r \mu / Q)$ & مسكن ها (شامل ترامادول) \\
\hline $\operatorname{qv}(1 \cdot)$ & $\operatorname{rr}(1 \cdot 19)$ & $10(\Lambda / 9)$ & داروهاى ضد افسردگى \\
\hline $19(F / 1)$ & $11(r / v)$ & $\Lambda(f / \varphi)$ & داروهاى آنتى سايكوتيك \\
\hline IV $(r / 9)$ & $1 \cdot(r / F)$ & $V(r)$ & داروهاى ضد فشار خون \\
\hline $10(T / T)$ & $\wedge(r / \Lambda)$ & $V(F)$ & داروهاى قلبى \\
\hline $\operatorname{Ir}(r / 9)$ & $\varphi(r)$ & $\varepsilon(r / \Delta)$ & ساير داروها \\
\hline$|r|(r \Delta / 9)$ & $G V(Y Y / \Lambda)$ & $\Delta F(r))$ & مصرف بيشتر از يك دسته دارو \\
\hline $\operatorname{l\in } \wedge(1 \cdots)$ & $r q q(1 \cdots)$ & $\operatorname{IVF}(1 \cdots)$ & جمع كل \\
\hline
\end{tabular}


جدول זّ: دلايل ذكر شده توسط بيماران براى اقدام به خودكشى

\begin{tabular}{|c|c|c|c|c|c|c|c|c|c|}
\hline \multirow[t]{3}{*}{$P$ value } & \multirow[t]{3}{*}{ جمع } & \multirow[t]{3}{*}{ ساير } & \multirow{3}{*}{ ع على } & مشاجره با & & & \multirow{3}{*}{\multicolumn{3}{|c|}{ (بر اساس اظدام به خودكش بيمار) }} \\
\hline & & & & خانواده يا & مشاجره & مشاجره با & & & \\
\hline & & & & همسر همراه & با همسر & خانواده & & & \\
\hline \multirow{6}{*}{.$/ 1 r \Delta$} & $V Y$ & 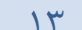 & If & $\hat{A}$ & 16 & r) & " & & \\
\hline & $1 \ldots$ & $1 / 11$ & $19 / 4$ & $11 / 1$ & $T Y / T$ & $r q / r$ & درصد & مرد & جنسيت \\
\hline & IQT & 10 & T\& & $r$. & $\Delta F$ & rर & تعداد & & \\
\hline & $1 \cdots$ & $9 / 1$ & IV & $\mid r / 1$ & $\Gamma \Delta / r$ & $T Y / \Lambda$ & درصد & زن & \multirow{3}{*}{ كل } \\
\hline & rTD & rA & $f$. & rA & v. & $\Delta 9$ & تعداد & & \\
\hline & $1 \ldots$ & $\mid r / T^{q}$ & $I V / \Lambda$ & $\mid r / F$ & rו/ & $r \varepsilon / T$ & درصد & & \\
\hline
\end{tabular}

قابل ملاحظه اى را به خود اختصاص داده بود و همجنين

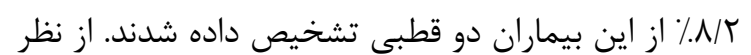

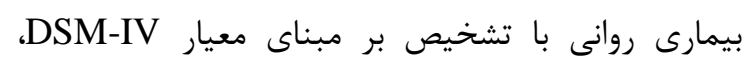

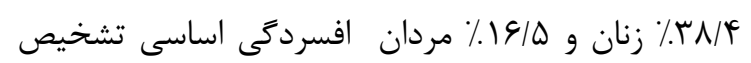

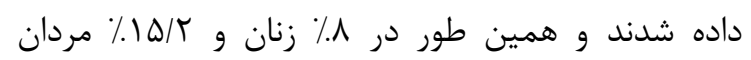

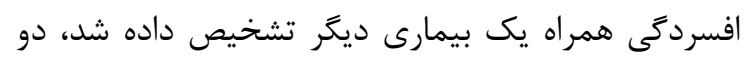

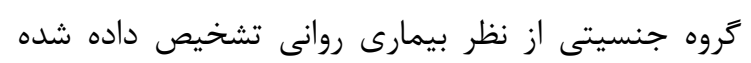

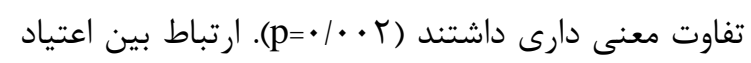

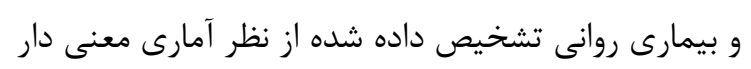

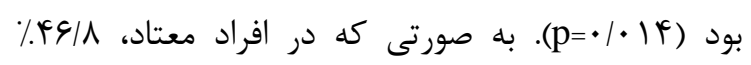

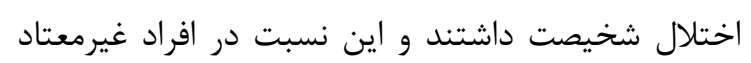

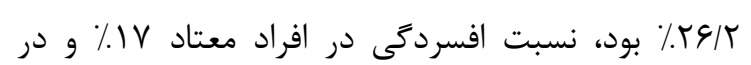

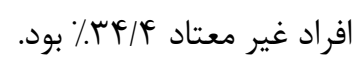

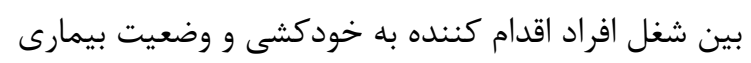

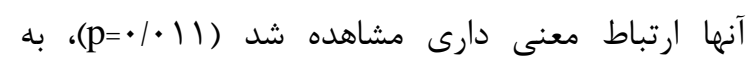

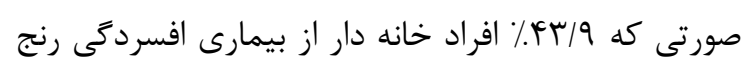

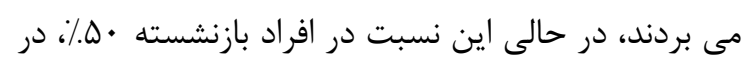

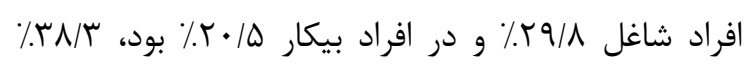

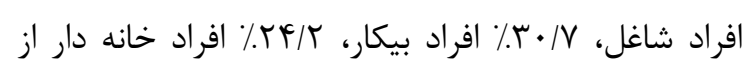
بيمارى اختلال شخصيت رنج مى بردند.
شايع ترين داروهاى مورد استفاده به ترتيب بنزوديازيين

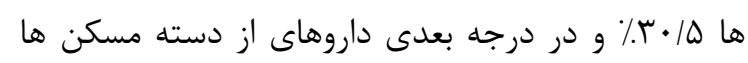

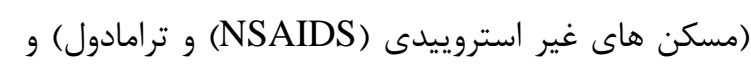

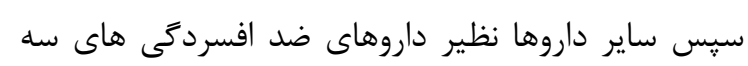

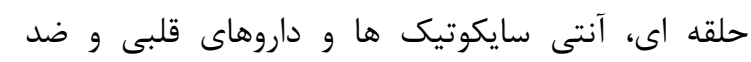

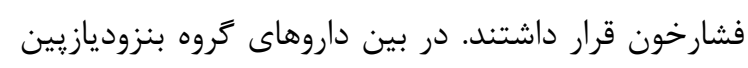
ها بيشترين داروى استفاده براى خودكشى آلريرازولام دارين

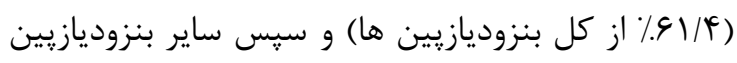

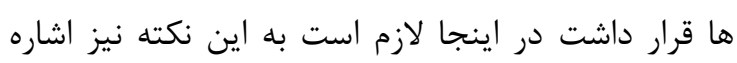

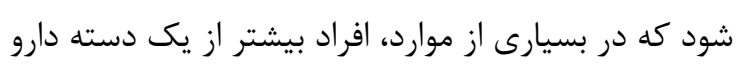

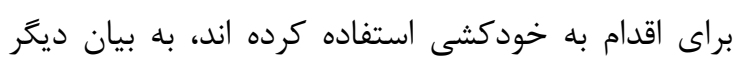

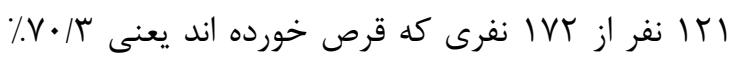

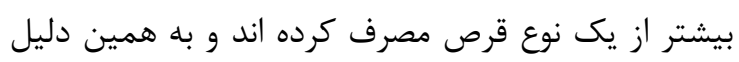

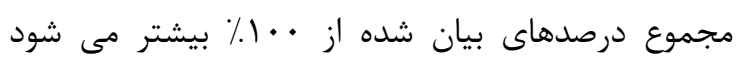

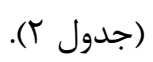

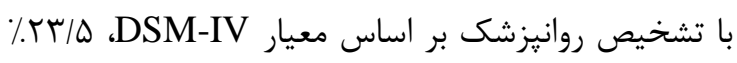

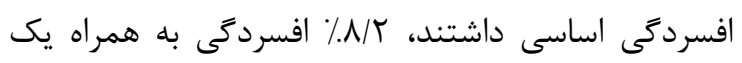

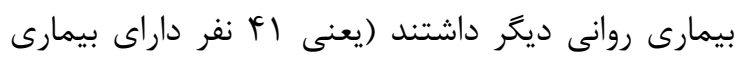

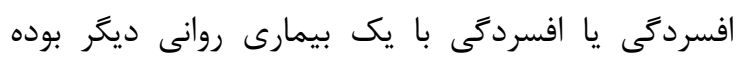

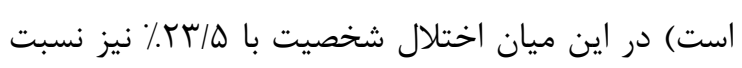


در يك مطالعه ى انجام گرفته در اصفهان نيز اين نتيجه

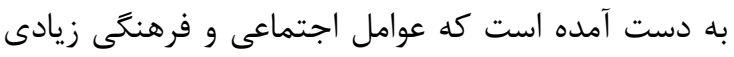
باعث ايجاد رفتارهاى منجر به خودكشى در بين زنان مي أنى

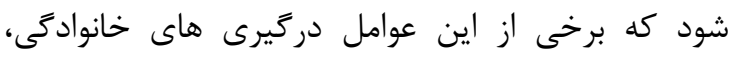
ازدواج و مشكلات با همسر، تعصبات اجتماعى و انتظارات إنى

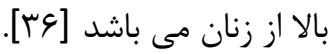

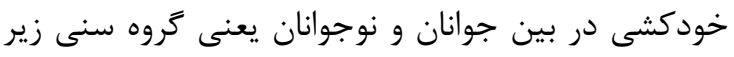

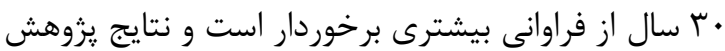

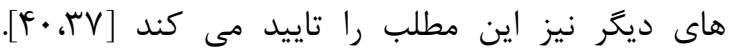
همانطور كه نتايج اين تحقيق نشان مى دهد بالاترين نرخ

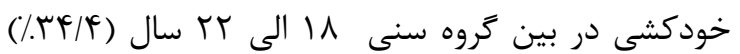
مى باشد كه اين يافته با نتايج يزوهش دود هاى انجى انجام شده توسط محمدى و همكاران در نيشابور و ظهور و همكاران

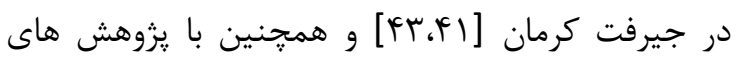

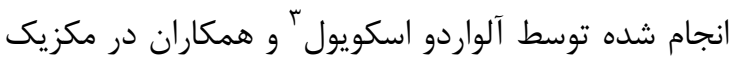

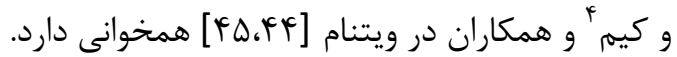
به طوركلى بر طبق مطالعات انجام كرفته دومين علت اصلى مرى و مير در بين جوانان خودكشى مى بى باشد.

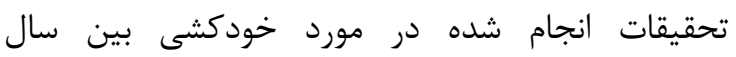

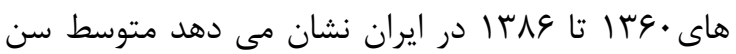

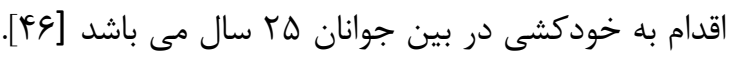
مطالعه ديخرى كه در مركز اورزانس شهر جيرفت (كرمان)

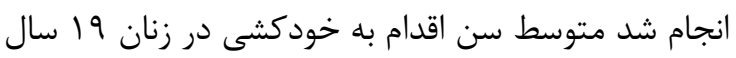
و در مردان FF سال بدست آمد [ب [F]. در اين يزوهش بين علت اقدام به خودكشى و سطوح

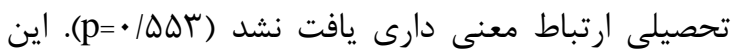

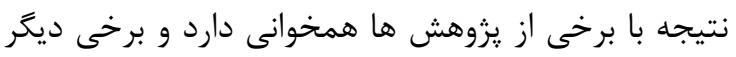

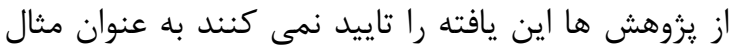
در يك بررسى سيستماتيك از خودكشى در ايران ارتباط

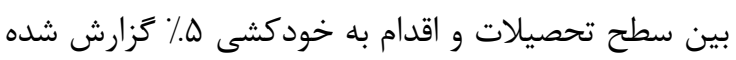

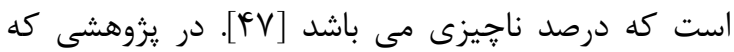
توسط ظهور و همكاران در مركز اورزانس شهر جيرفت انجام شده است. نشان مى دهد كه بين خودكشى و وران دران

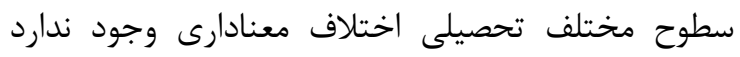

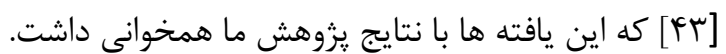

3 -Alvarado-Esquivel 4 -kim
بر اساس آنجه خود بيمار به عنوان علت خودكشى ذكر بران

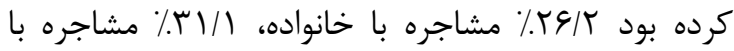

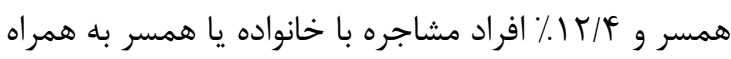

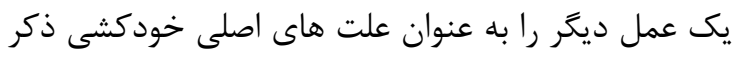

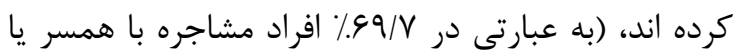

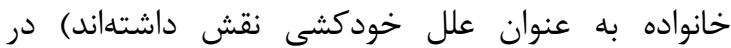

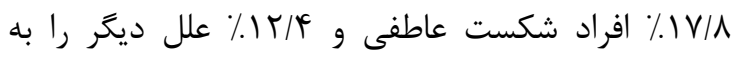
عنوان علت خودكشى ذكر كرده اند رابطه معنى دارى بين

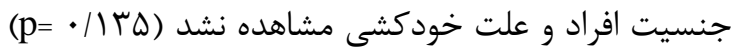

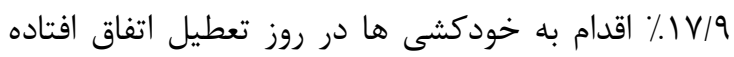

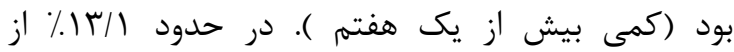
خودكشى ها در حضور ديكران رخ داده است.

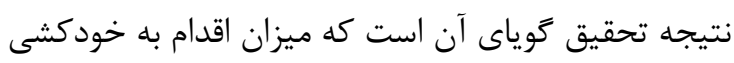
در بين زنان به طور معنى دارى بيشتر از مردان است و از از

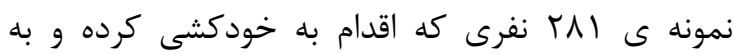

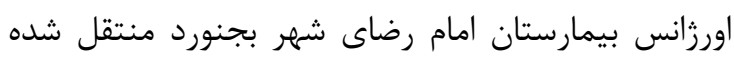

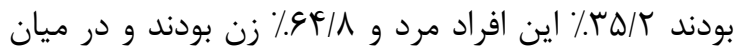
زنان نيز اقدام به خودكشى در بين زنان متاهل بيشتر از

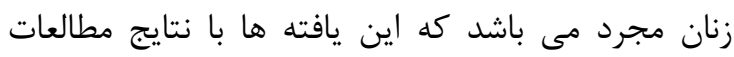

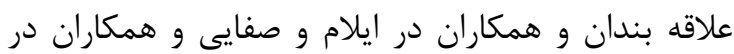

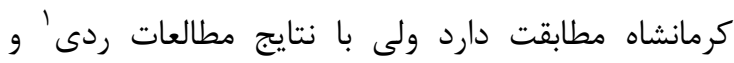

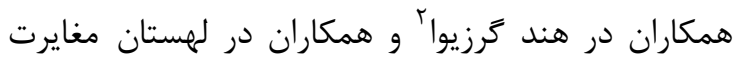

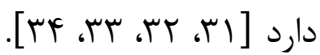

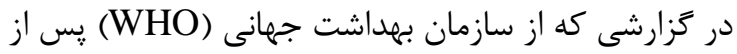

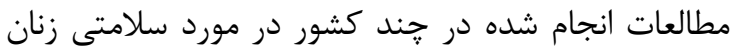

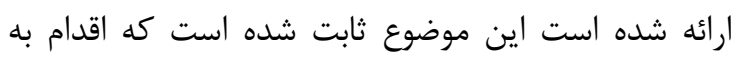

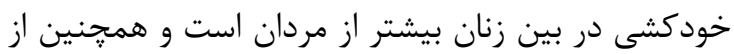

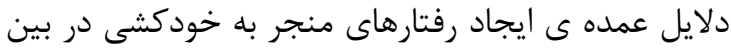

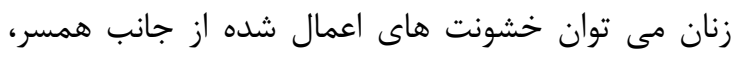

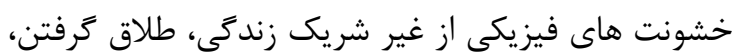
بيوه شدن و سوء استفاده هاى جنسى در دوران كودكى را ران

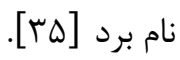


عوامل استرس زا مى شود و در نهايت عوامل استرس زا

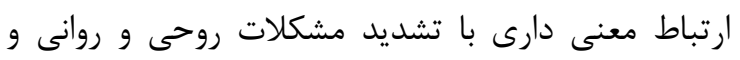

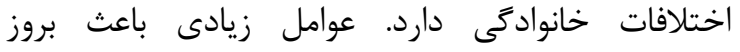

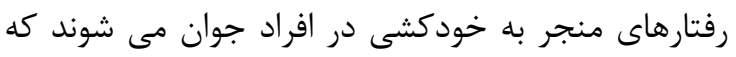

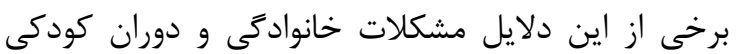

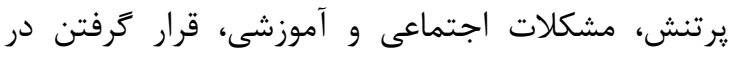

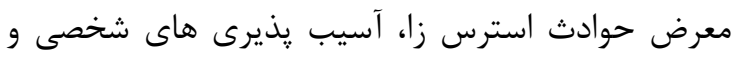

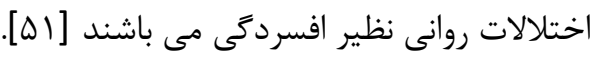

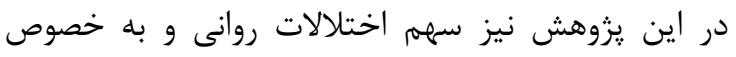

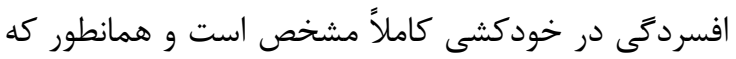

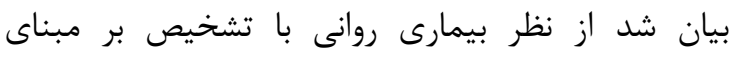

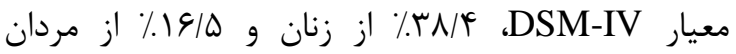

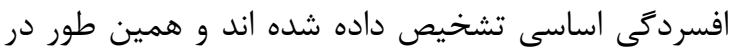

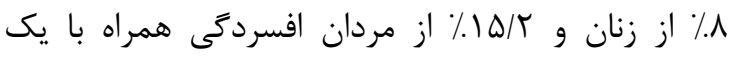

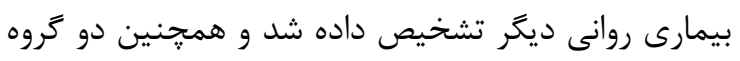

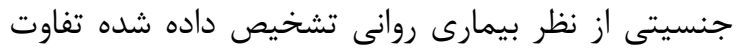

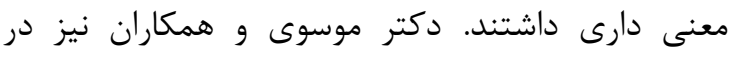

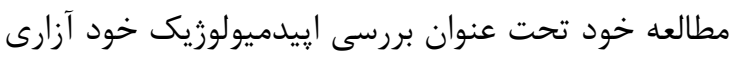

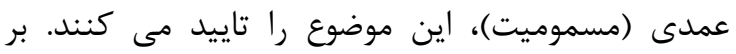

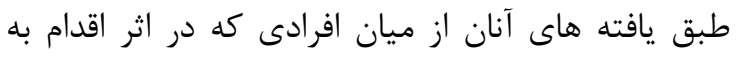

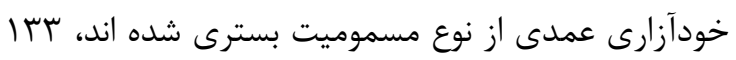

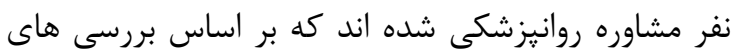

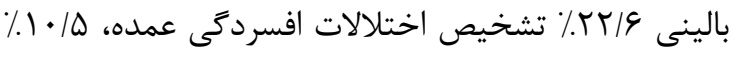

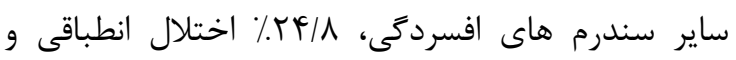

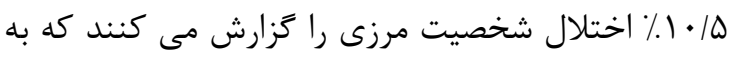

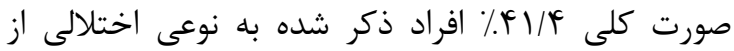
افسردكى را داشته اند [^].

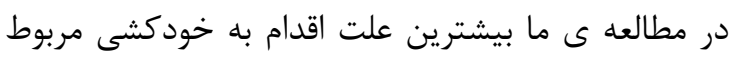
به دركيرى هاى خانوادىى و مشاجره با همسر مى بـ باشد.

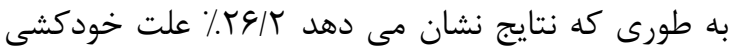

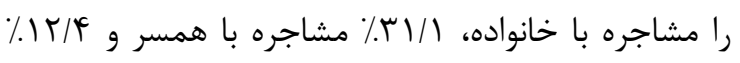
افراد مشاجره با خانواده يا همسر به همراه يك عادها آنامل ديخر

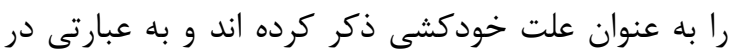

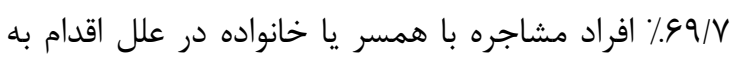

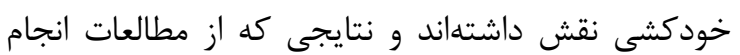

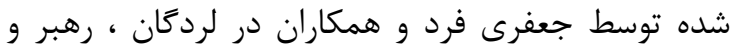

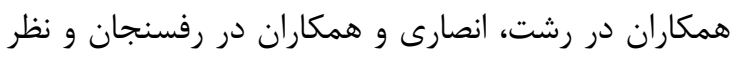

از طرف ديكر در مطالعات بهمنش يور و همكاران در زاهدان و كيوان آرا و همكاران در اصفهان نشان داده شده دان

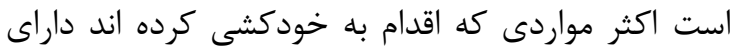

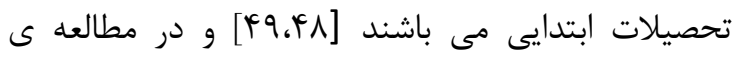

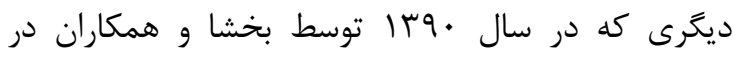
كلستان انجام گرفته است نيز اكثر افرادى كه اقدام به خودكشى كرده بودند از نظر تحصيلات در سطح پإيينى

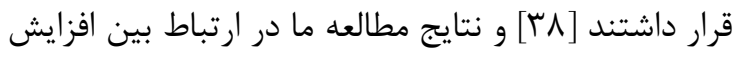
خودكشى در سطح تحصيلات ابتدايى با مطالعات انجام شده در زاهدان و كلستان و اصفهان همخوانى نداشت البته بايد توجه داشت كه اين تفاوت ها مى تواند كروه هاى شركت كننده در مطالعات نيز باشد و اين امكان

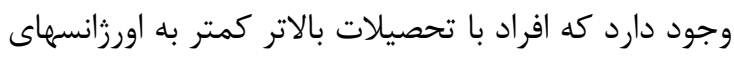

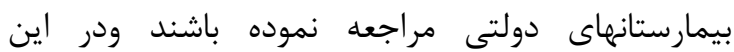
مطالعات وارد نشده باشند.

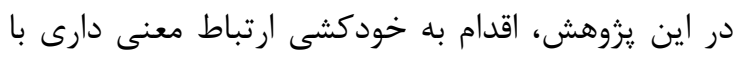

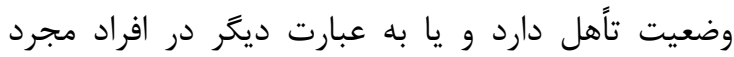

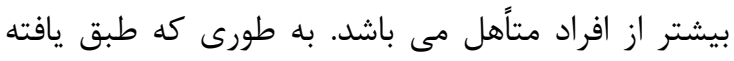

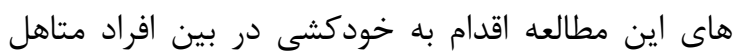

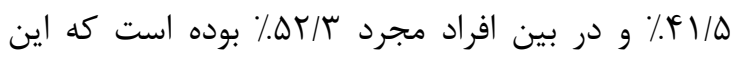

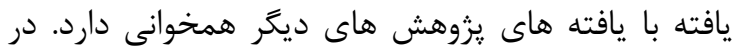

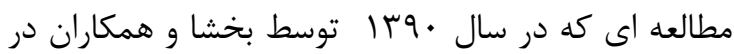

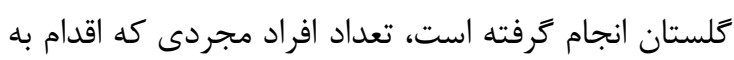

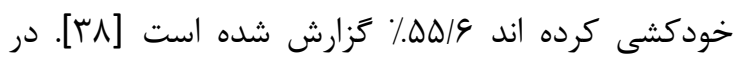
مطالعه ى ديگر كه توسط فريبرز جبارى فرد و همكاران

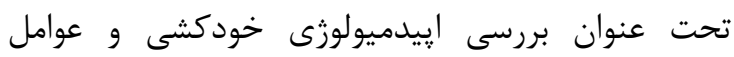

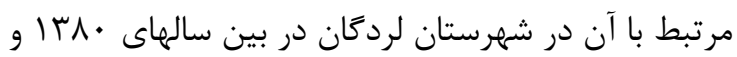

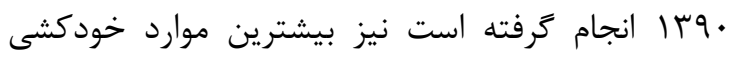

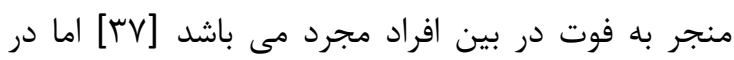

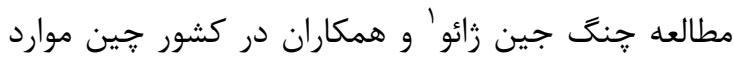

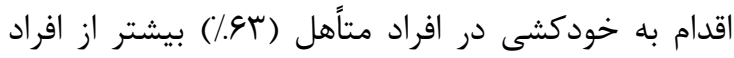
مجرد مى باشد كه با نتيجه مطالعه ما همخوانى ندارد

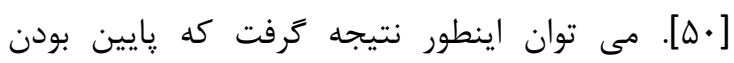

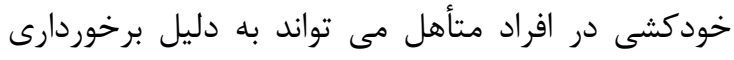

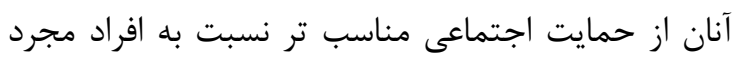

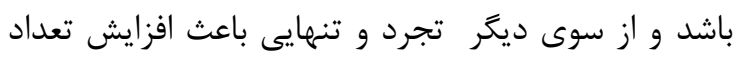

\section{1-Cheng-jin Zhao}


نتايج به دست آمده از اين تحقيق نشان مى دهد كه رايجترين روش خودكشى خوردن قرص بوده است و در ميان قرص ها نيز استفاده از داروهاى روانيزشكى از جمله

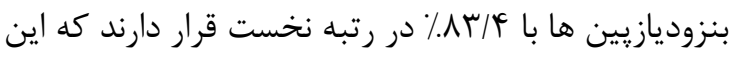
موضوع از جند بعد داراى اهميت است:

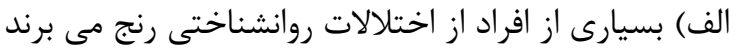

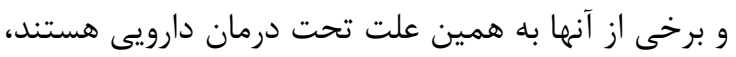

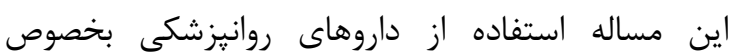

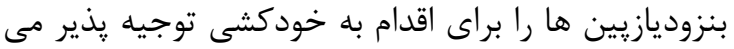

ب) در بسيارى از منازل مقادير زيادى از داروهاى خواب

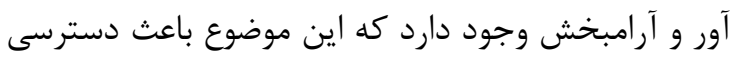

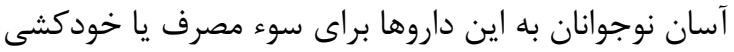

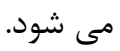
ج) يزشكان به فراوانى اقدام به تجويز اين دسته از داروها مى نمايند و اين خود باعث دسترسى هرجه بيشتر مردم به اين دسته از داروهاست. د) و متاسفانه بسيارى از داروخانه ها اقدام به فروش آر است داروهاى روانيزشكى بخصوص خواب آور ها، بدون نسخه يزشك مى نمايند و اين موضوع باعث دسترسى هر جهات

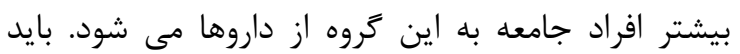
توجه داشت كه بسيارى از افرادى كه اقدام به خريد اين داروها از داروخانه مى كنند مبتلا به افسردىى هاى شديد إندايد

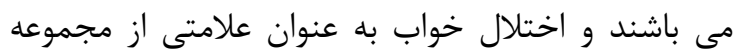

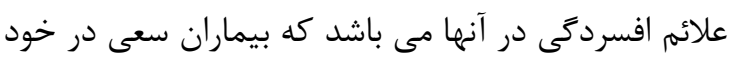

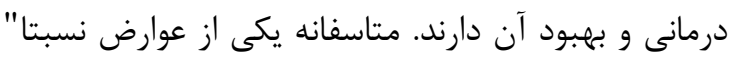

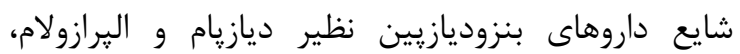

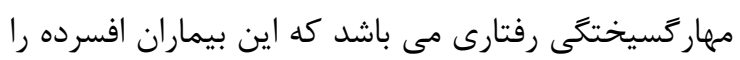
در خطر بالاترى براى خودكشى قرار مى دهد.

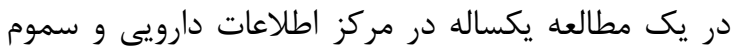

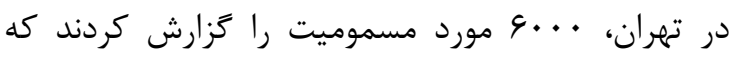
اقدام به خودكشى هَّ٪ از كل مسموميت ها را شامل مى ملى شد كه در اين ميان داروهاى موثر بر CNC مانند

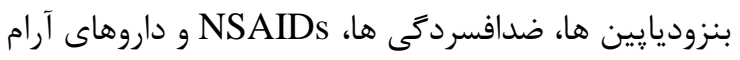

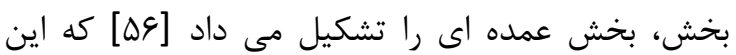

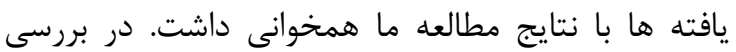
إييدميولوزيك موارد خود كشى عمدى (مسموميت) در
زاده و همكاران در ايران (مطالعه مرورى) به دست آمده

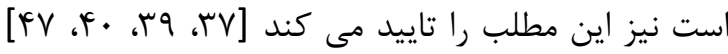
البته بايد توجه داشت كه علت اقدام به خودكشى بر اساس علت ذكر شده توسط خود بيمار زَارش شده است و وائ اين

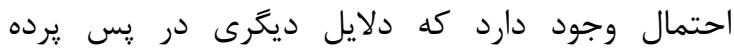
خودكشى بيمار وجود داشته باشد كه شخص تمايلى به

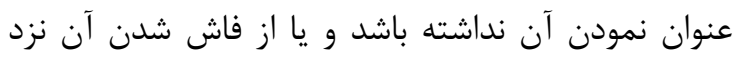

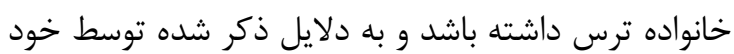
بيمار به يرسشكر نمى توان اطمينان بالايى داشت.

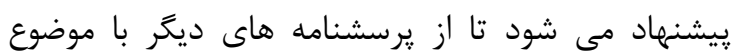

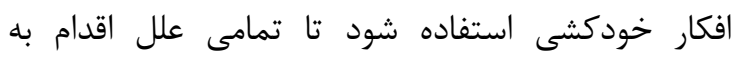
خودكشى مورد بررسى قرار بخيرد. محيط هاى خانوادگى مختل شده و دركيرى هاى بين

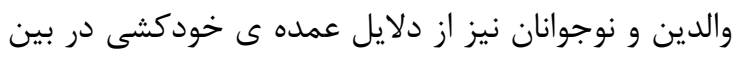

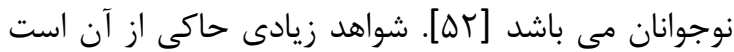

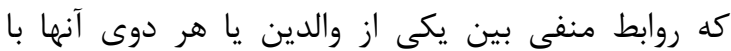

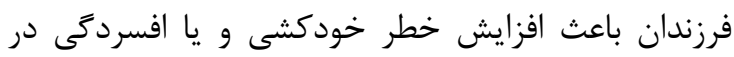

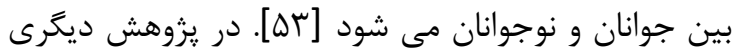

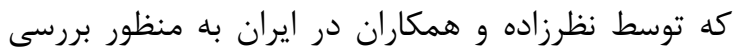

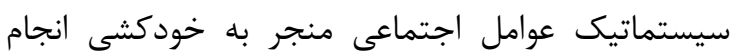

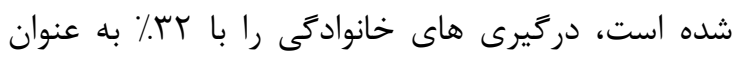
شايع ترين علت اقدام به خودكشى ارزيابى كرده اند كه اين ميزان در استان كيلان هذه٪ تزارش شده است. در

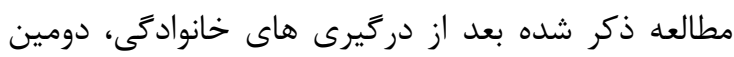

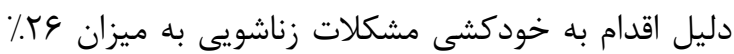

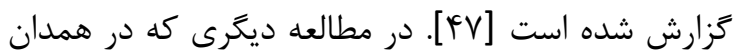
انجام شده است دليل اكثر خودكشى هاى انجام شده

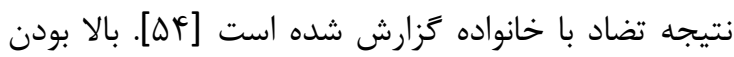
اين ميزان هم در اين يروهش و هم در يزوهش هاى

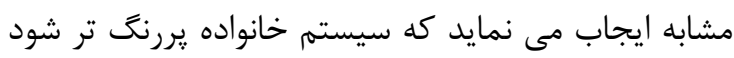

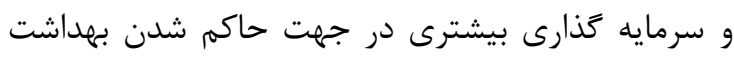
روانى مناسب در ميان اعضاء خانواده و روشهايى براى دئ دائ كسب مهارتهاى زندكى و تقويت مكانيزم هاى مداخله در

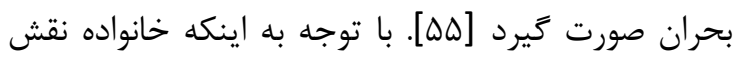

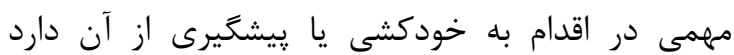
بايستى برنامه هاى آموزش خانواده در اولويت روش هاى بيشخيرى از خودكشى قرار بخيرد. 
منجر به مرگ) در اين مطالعه وارد نشده است و اين

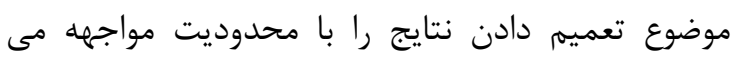

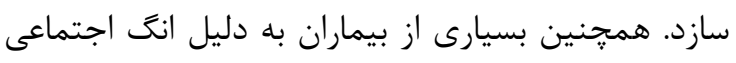

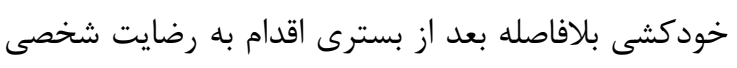

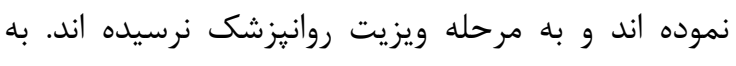
همين دليل وارد مطالعه نشده اند. بنابراين تعميم يافتن

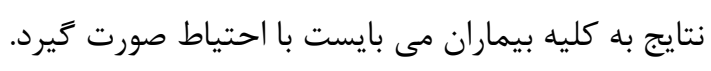

\section{نتيجه تيرى}

لازم است در سياست كذارى هاى كشور به موضوع

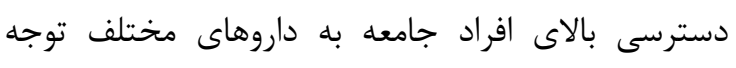

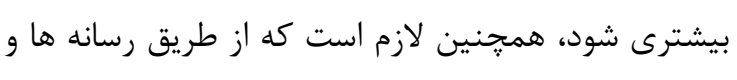

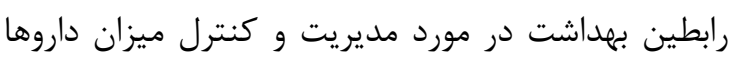

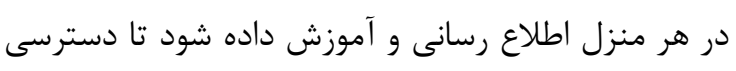

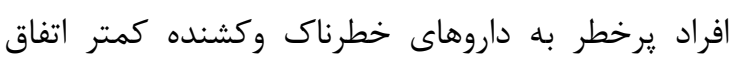
بيافتد.

\section{تشكر و قلروراذى بئن}

اين طرح مصوب معاونت يزوهشى دانشعاه علوم يزشكى شاري

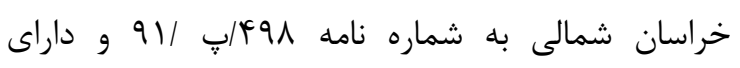

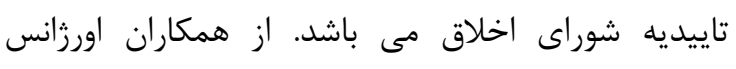

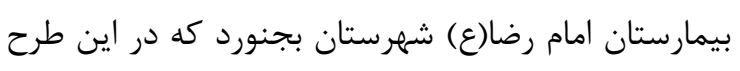
همكارى داشتند تقدير و تشكر مى كرددام
شهرستان شاهرود كه توسط دكتر موسوى و همكاران

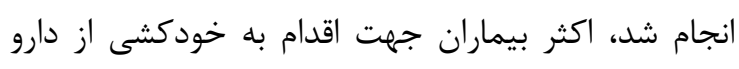

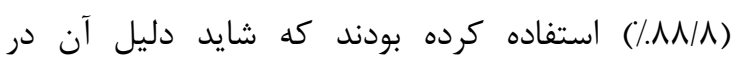
دسترس بودن و تهيه راحت آن، آشنايى با داروها و نيز

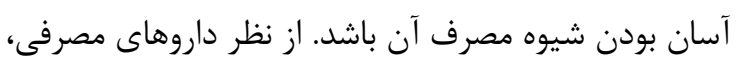

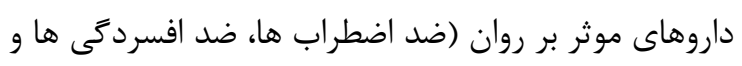

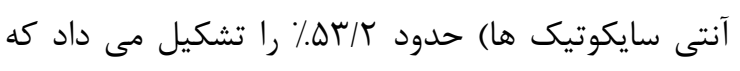

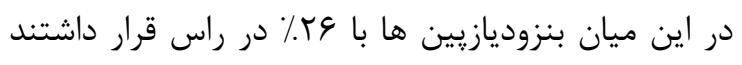

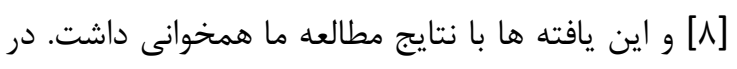

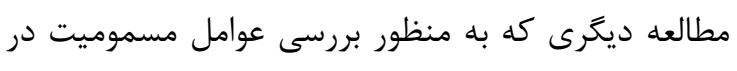

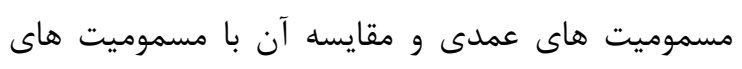

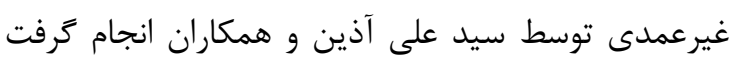

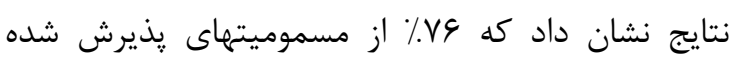

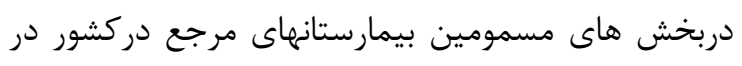

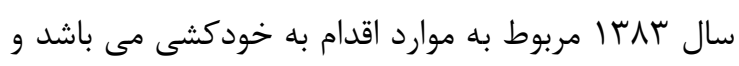

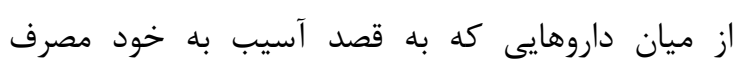

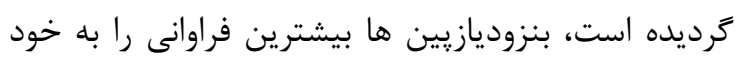

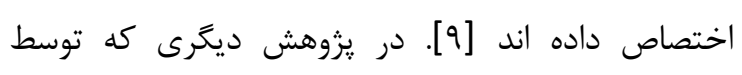

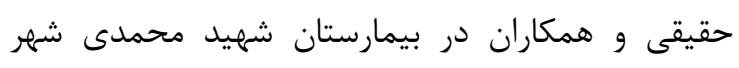

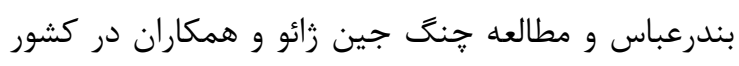

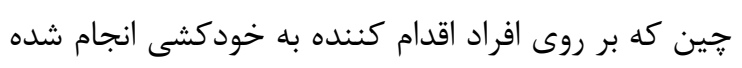

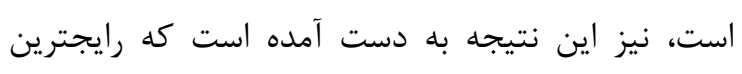

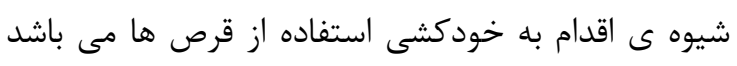

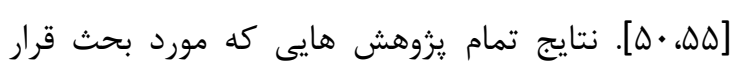

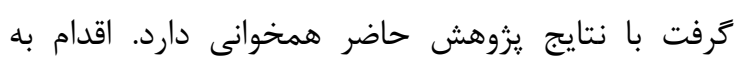

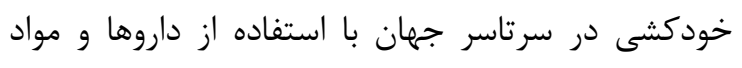

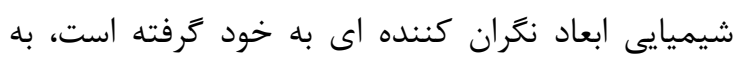
طورى كه خودكشى با قرص ها و مواد شيميايى به عنوان

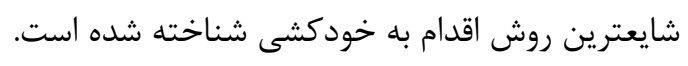

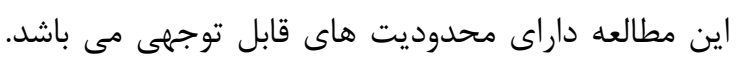
يكى از محدوديت هاى اصلى اين مطالعه اين است كه تنها ماريا

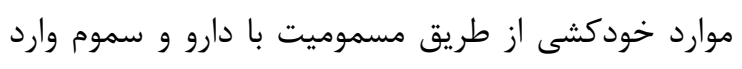

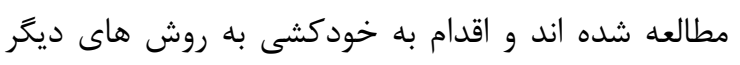

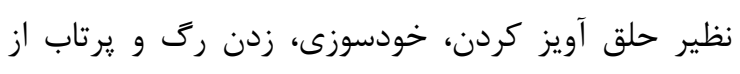
بلندى به اورزانس هاى بيمارستان هاى ديكر ارجاع داده

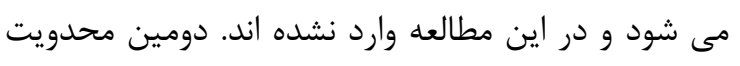
اين مطالعه اين است كه موارد خودكشى موفق (خودكشى مورد 


\section{References}

1. Murphy sl, Deaths: final data for 1998, Natl vital stat rep. 2000; 13(11):1-105.

2. Li y, li y, cao j, Factors associated with suicidal behaviors in mainland china: a meta-analysis, Bmc public health 2012;12(1):524.

3. Rozanov va, mid'ko aa. Personality patterns of suicide attempters: gender differences in ukraine, The spanish journal of psychology 2011;14(02):693-700.

4. Clayton d, barcel a, The cost of suicide mortality in new Brunswick 1996, Chronic dis can. 1999; 13(2):89-95.

5. Hojjat s. k., Hamidi M, Addiction And Social Harms: Arvij Publications, North Khorasan University of Medical Science Deputy of Research 2013 [persian].

6. World health organization, Suicide prevention (supre) 2003, [last accessed on 2012 aug 31; cited 2012 sep 9] Available from: Http://www.who.int/mental_health/prevention/suicide/suicideprevent/en.

7. Ghoraishi s.a., mousavinasab s.n.,Systematic review studies on suicide and attempted suicide in iran ,iranian journal of psychiatry and clinical psychology(thought and behavior) 2008;14(2): 121-115. 8. Mousavi s.a., khosravi a., hasani m.h., jahani $\mathrm{z}$, epidemiologic study ofdeliberateself-injury( poisoning) in the sahroud city, Journal of science and health 2007; 2(2):38-44.

9. Azin s.a., shahidzadeh mahani a., \&ebadi m., omidvari s., \&montazeri a,The deliberatepoisoning of poisoning incomparison withunintentionalpoisoningandrelatedvariables , Journal of epidemiologyiran, 2008;4(2):7-17.

10.Moradi s., khademi a, Study of suicides resulting indeathin iranin comparison withthe globalrates, Journal offorensic medicine 2002;27(8):16-21.

11.Sadock bj, Sadock va kaplan and sadock's synopsis of psychiatry behavioral science clinicalpsychiatry, 10 th ed. Philadelphia: lippincott willwiams and wilkins 2007, P. 897-906.

12.Smith jc, mercy ja, conn jm, Marital status and the risk of suicide, American journal of public health, 1988;78(1):78-80.

13.Luoma jb, pearson jl, Suicide and marital status in the united states, 1991-1996: is widowhood a risk factor? American journal of public health 2002;92(9):1518-22.

14.Brent da, perper ja, allman cj, Alcohol, firearms, and suicide among youth, $j$ am med assoc, 1987; 257: $3369-3372$.

15.Lesage ad, boyer r, grunberg f, vanier c, morissette r, menard-buteau c, "et al", Suicide and mental disorders: a case-control study of young men, Am j psychiatry, 1994; 151: 1063 - 1068.

16. Rich cl, runeson bs, Similarities in diagnostic comorbidity between suicide among young people in sweden and the united states,actapsychiatr scand, 1992; 86: 335 - 339.

17. Shaffer d, gould ms, fisher p, trautman p, moreau d, kleinman m, "et al", Psychiatric diagnosis in child and adolescent suicide,Arch gen psychiatry,1996; 53: 339 -348..

18. Marttunen $\mathrm{mj}$, aro hm, henriksson mm, lonnqvist jk, Mental disorders in adolescent suicide, Dsmiii-r axes i and ii diagnoses in suicides among 13- to 19-year-olds in finland, Arch gen psychiatry, 1991; 48:834-839.

19.Rich cl, young d, fowler rc, San diego suicide study: i. Young vs old subjects, Arch gen psychiatry 1986; $43: 577-582$.

20.Runeson bs, Mental disorder in youth suicide: dsm-iiir axes i and ii, Actapsychiatr scand 1989; 79: $490-497$.

21.Gilchrist h, howarth g, sullivan g, The cultural context of youth suicide: unemployment, identity and gender in australia.soc pol soc. 2007; 6:151-63.

22.Zare h, sayadi a, Prevalence of mental disorders and associated factors of suicidein patients referred to hospital emergency departments of imam ali ibnabitalib(as), J rafsanjanuni medsci 2009;3:222-38.

23. Hawton k, saunders ke, o'connor rc, Self-harm and suicide in adolescents, Lancet 2012;14(9834):2373-2382, Doi: 10.1016/s0140-6736(12)60322-5

24.Perry ij, corcoran p, fitzgerald ap, keeley hs, reulbach $\mathrm{u}$, arensman e, The incidence and repetition of hospital-treated deliberate self harm: findings from the world's first national registry, Plos one.2012; 14(2):e31663.doi:10.1371/journal.pone.0031663.[pmc free article][pubmed][cross ref] 
25.Beck fg r, du roscoat e, saias t, Tentatives de suicide etpenséessuicidaires en france en 2010 françois beck 88. Bhe.2011;14:488-492

26.Heron m, Deaths: leading causes for 2007, Natl vital stat rep,2011;59:1-95.

27.Sadock bj, sadock va.kaplan and sadock's comprehensive textbook of psychiatry, London:lippincott co; 2004.

28.Trivedi j., \&varma s. (2010). Suicidal behaviour assessment of people at-risksage publications, Pp. 42-65.

29. Stewart m. E., donaghey c., \&ebmeier k. P. (2008), Suicidal thoughts in youngpeople: their frequency and relationships with personality factors, Personalityand individual differences, 44: 809820.

30.Kolves $\mathrm{k}$, ide $\mathrm{n}$, de leo d, Suicidal ideation and behaviour in the aftermath of marital separation: gender differences, Journal of affective disorders 2010;120(1-3):48-53.

31.Alaghehbandan $\mathrm{r}$, lari ar, joghataei $\mathrm{m}-\mathrm{t}$, islami a, motavalian a, A prospective population-based study of suicidal behavior by burns in the province of ilam, iran. Burns. 2011;37(1):164-9.

32. Grzywa a, kucmin a, kucmin t, [suicide problems--epidemiology, factors, motives and prevention, Part ii], Polski merkuriusz lekarski: organ polskiego towarzystwa lekarskiego 2010;28(164):174-6.

33. Reddy M, Suicide incidence and epidemiology, Indian journal of psychological medicine, 2010;32(2):77.

34.Safaie $\mathrm{p}$, jahangiri $\mathrm{k}$, barkhordar $\mathrm{n}$, editors, Trend and factors influencing suicides in rural areas of kermanshah (in iran) during 7 years (2000-2006), Bioinformatics and biomedical engineering 2009 icbbe 2009 3rd international conference on; 2009: ieee[Persian].

35.Devries k, watts c, yoshihama m, kiss l, schraiber lb, deyessa n, "et al", Violence against women is strongly associated with suicide attempts: evidence from the who multi-country study on women's health and domestic violence against women. Social science \& medicine 2011;73(1):79-86.

36.Keyvanara $\mathrm{m}$, haghshenas a, The sociocultural contexts of attempting suicide among women in iran, Health care for women international 2010;31(9):771-83.

37.Jabari fard f., \&ghari olvije a., \&yazd khasti f., \&masoudi s, The epidemiology ofsuicide andits risk factors,lordegan,iran,in 2011 - 2001, Journal ofmedicalsciences of shahre kord.2013;15(6):75-86.

38. Bakhsha $\mathrm{f}$, behnampour $\mathrm{n}$, charkazi a, The prevalency of attempted suicide in golestan province, north of iran during 2003-07, Journal of gorgan university of medical sciences 2011;13(2):79-85.

39. Rahbar tm, orangpour r, mousavian rzs, davam f, Survey of suicidal epidemiologic fators in emergency ward patients of razi hospital, rasht. 2004.

40.Ansari a., khodadadi zade a., sayadi a., negahban t., tavakoli $\mathrm{m}$, Casesof suicideandits risk factorsinali ibn abi talibhospital,rafsanjan,iran in 2007-2006 , Journal ofnursing, midwiferyandalliedhealth inmedical sciences of rafsanjan university 2010;5(1):38-44.

41. Mohammadi gh, saadaty a, Survey of epidemiology and etiology of suicidal attempt and relation to socio demographic factors in the administrated emergency unit central hospital of neishabur in 2003, Quarterly journal of fundamentals of mental health, 2004:23-4.

42. Ghaleiha a, afzali s, bazyar $\mathrm{m}$, khorsand $\mathrm{f}$, torabian $\mathrm{s}$, Characteristics of hospitalized patients following suicide attempt in hamadan district, iran, Oman med j, 2012;27(4):304-9.

43.Zohor a, torabi $\mathrm{m}$, pasandeh $\mathrm{h}$, Epidemiology of suicide in reffering to emergency center of center of jiroft of kerman, 2001.

44.Alvarado-esquivel c, sánchez-anguiano lf, arnaud-gil ca, hernández-tinoco j, molina-espinoza lf, rábago-sánchez e, Socio-demographic, clinical and behavioral characteristics associated with a history of suicide attempts among psychiatric outpatients: a case control study in a northern mexican city, International journal of biomedical science: ijbs. 2014;10(1):61.

45.Kim dr, ali m, thiem vd, wierzba tf, Socio-ecological risk factors for prime-age adult death in two coastal areas of vietnam, Plos one, 2014;9(2).

46. Shirazi h, hosseini m, zoladl m, malekzadeh m, momeninejad m, noorian k, "et al", Suicide in the islamic republic of iran: an integrated analysis from 1981 to 2007, 2012. 
47.Nazarzadeh m, bidel z, ayubi e, asadollahi k, carson kv, sayehmiri k, Determination of the social related factors of suicide in iran: a systematic review and meta-analysis, Bmc public health, 2013;13(1):4.

48.Poor fb, tabatabaei sm, bakhshani n-m, Epidemiology of suicide and its associated sociodemographic factors in patients admitted to emergency department of zahedan khatam-al-anbia hospital, International journal of high risk behaviors \& addiction 2014;3(4).

49. Keyvanara m, mousavi sg, karami z, Social class status and suicide characteristics: a survey among patients who attempted suicide in isfahan, Materia socio-medica 2013;25(1):56.

50. Cheng-jin zhao, xing-bo dang, xiao-li su, jia bai, long-yang ma, Epidemiology of suicide and associated socio-demographic factors in emergency department patients in 7 general hospitals in northwestern china, Med sci monit. 2015; 21: 2743-2749.

51.Beautrais al, Risk factors for suicide and attempted suicide among young people, Australian and new zealand journal of psychiatry,2000;34(3):420-36.

52.Peña jb, kuhlberg ja, zayas lh, baumann aa, gulbas 1, hausmann-stabile c, "et al", Familism, family environment, and suicide attempts among latina youth, Suicide and life-threatening behavior 2011;41(3):330-41.

53.Consoli a, peyre h, speranza m, hassler c, falissard b, touchette e, "et al", Suicidal behaviors in depressed adolescents: role of perceived relationships in the family, Child adolesc psychiatry ment health 2013;7(1):8.

54.Amiri b, pourreza a, rahimi foroushani a, hosseini sm, poorolajal $\mathrm{j}$, Suicide and associated risk factors in hamadan province, west of iran, in 2008 and 2009, Journal of research in health sciences, 2012;12(2):88-92.

55.Haghighi h, golmirzaee $\mathrm{j}$, mohammadi $\mathrm{k}$, moradabadi as, dadipoor $\mathrm{s}$, hesam aa, Investigating the relationship between the demographic variables associated with suicide in different seasons among suicidal people in the shahid mohammadi hospital, bandar abass, iran, Journal of education and health promotion. 2015;4[Persian].

56.Karami m., ebrahim zade m., yousefi p., khani k, Investigatethe causes ofdrug poisoningin boali and nime shaban hospital,sari,iran,in 2002- 2000, Razijournal of medical sciences 2004;11(42)629-35. 


\title{
Demographic characteristics of patients with suicide attempt in Bojnurd;2014
}

\author{
Hojjat $S K^{1}$, Hatami $S E^{2}$, Norozi Khalili $M^{3}{ }^{*}$, Kazemi $S^{4}$, Danesh $M^{5}$, \\ Samadi bilehsavar $A^{6}$, Naghdi Pour $J^{7}$, Kamkar khabushan $M^{8}$, Ansari $H^{8}$ \\ ${ }^{1}$ Assistant professor, Addiction and Behavioral Sciences Research Center, North Khorasan \\ University of Medical Sciences, Bojnurd, Iran. \\ ${ }^{2} \mathrm{MSc}$ of epidemiology, Addiction and Behavioral Sciences Research Center, North Khorasan \\ University of Medical Sciences, Bojnurd, Iran. \\ ${ }^{3}$ Department of community medicine and ethic, North Khorasan University of Medical \\ Sciences, Bojnurd, Iran. \\ ${ }^{4}$ M.As of clinical psychology. Esfarayen Faculty of Medical Sciences, Esfarayen, Iran. \\ ${ }^{5}$ PHD student of counseling, Islamic Azad University, Bojnurd branch, Bojnurd, Iran. \\ ${ }^{6}$ Resident of psychiatry, Iran University of Medical Sciences, Tehran, Iran. \\ ${ }^{7}$ MA student of psychology, Islamic Azad University, Bojnurd branch, Bojnurd, Iran. \\ ${ }^{8}$ B.S nursing, Imam Reza Hospital, North Khorasan University of Medical Sciences \\ . Bojnurd, Iran. \\ *Corresponding Author: Norozi Khalili Mina, Department of community medicine, school \\ of medicine, North Khorasan University of Medical Sciences. shahriar street, Bojnurd, Iran \\ Email: mina.norozi@yahoo.com
}

\section{Abstract}

Background \& Objectives: suicide is one of the main reasons of mortality in the world and many countries involve with this major health issue. Pattern of suicide attempt is different in countries. Aim of this study was to assess the pattern of suicide attempt for suicide in patients who admitted in hospital.

Material \& Methods: this research was a descriptive analytical study. Participants include all patients who admitted along one year (2013-2014) in Imam Reza hospital in Bojnurd city with suicide attempt (based on psychiatric interview). Require data such as pattern of suicide and kind of drug used collected by researcher designed checklist. Data were analyzed by SPSS. Chi-square test was used to analyze the data.

Result: 281 patients with suicide attempt included in this study. $35.2 \%$ of samples were women and $64.8 \%$ was men. Mean age of samples was $24 \pm 9.07$ year. We found a significant relation between variables such as age, gender and marital status and reason of suicide attempt. Drug poisoning was the most pattern of suicide attempt. Benzodiazepines were the most prevalence drugs used by patients for suicide. Argument with family or spouse was the most reason for suicide attempt based on patients self report.

Conclusions: The policy of the country is necessary to pay more attention to the issue of access of individuals to various drugs, as well as through the media and volunteers to manage and control the amount of medication in each house to inform and educate access to the people at high risk of unsafe drugs, less fatal to happen.

Key words: suicide attempt, drugs, pattern of suicide attempt 